\title{
Culture of the Prawn Larvae with Micro-Particulate Diets
}

\author{
Akio Kanazawa, ${ }^{* 1}$ Shin-ichi Teshima, ${ }^{* 1}$ Hiroshi Sasada, ${ }^{* 1}$ \\ and S. ABDEL RaHMAN*2 \\ (Received July 10, 1981)
}

\begin{abstract}
Several types of micro-particulate diets were prepared and their dietary values for the larvae of a prawn Penaeus japonicus were evaluated. Some microencapsulated diets with nylon-protein membranes (Nylon-MED) and with zein-membranes (Zein-MED) supported the growth of prawn larvae from $z_{0 e a_{1}}$ to post-larvae ${ }_{1}$. In terms of both survival and growth rates, however, the powdered diets with zein as a coating (Zein-MCD) gave better results than the Nylon-MED and ZeinMED. The dietary value of the Zein-MCD containing a defined diet was almost comparable to those of live feeds, Chaetoceros gracilis and Artemia salina; the prawn which received the ZeinMCD grew up from zoea to $_{1}$ post-larvae ${ }_{1}$ in 8 days with a survival rate of $94 \%$.
\end{abstract}

The seedling production of the prawn Penaeus japonicus has been depending on a live food such as the diatoms and Artemia salina. ${ }^{1-4)}$ The mass culture of planktonic organisms not only requires lots of manual help and expensive equipments but also fluctuates according to weather conditions, etc. In the previous studies, therefore, we have attempted to rear the larval prawns with microparticulate diets (MD). ${ }^{s, a)}$ In the present study, several types of MD were further prepared and their dietary values for the larval prawns were examined by the feeding trials. This paper deals with these results, indicating the success in rearing the prawn larvae from zoea ${ }_{1}$ to postlarvae $\left(\mathbf{P}_{1}\right)$ with the MD comprising all chemically known compounds.

\section{Materials and Methods}

\section{Preparation of Diets}

Table 1 shows the composition of diets examined in this study. All ingredients or compounded diets were powdered into fine particles $(<10-20 \mu \mathrm{m}$ diameters) prior to the preparation of MD. Diets 1,2 and 3 are the diets encapsulated with a nylon-protein membrane (NylonMED) which were prepared by the interfacial polymerisation procedure of CHANG et al. ${ }^{7}$ as described in the previous papers. ${ }^{5)}$ The composition of artificial diet, diet $\mathrm{A}$, was the same as reported previously ${ }^{83}$ and contained the following ingredients $(\mathrm{g} / 100 \mathrm{~g}$ dry diet): glucose 5.5 , sucrose 10, $\alpha$-starch 4.0, glucosamine- $\mathrm{HCl} 0.8$, casein 50 , pollack liver oil 6.0 , cholesterol 1.0 , sodium citrate 0.3 , sodium succinate 0.3 , minerals 8.52 , vitamins 3.2, cellulose powder 7.36, and agar 3.0. Mysid extract was supplied from a certain company in Japan. To $2 \mathrm{~g}$ of diet $\mathrm{A}$ or mysid extract, chicken egg $(1.34 \mathrm{~g}$ in dry weight $)$ was added as the homogenate $(20 \mathrm{~m} l)$ of whole chicken eggsdistilled water $(1: 1, \mathrm{v} / \mathrm{v})$ and encapsulated.

Diets $4,5,6,7,8$, and 9 are the diets encapsulated with a zein membrane (Zein-MED) by using sodium hydroxide (NaOH-method) or ethanol (EtOH-method) as follows. Zein-MED ( $\mathrm{NaOH}$-method): The powdered diet $(7 \mathrm{~g})$ was suspended in the $\mathrm{NaOH}$ solution $(\mathrm{pH} 12,70 \mathrm{ml})$ containing zein ( $1.4 \mathrm{~g}$ ) with continuous stirring by means of a magnetic stirrer. The suspension was diluted with distilled water $(120 \mathrm{~m} l)$ and acidified with acetic acid to a $\mathrm{pH}$ value of 4.5 to form the Zein-MED. Zein-MED (EtOH-method): The powdered diet $(6 \mathrm{~g})$ was mixed with zein $(1.2 \mathrm{~g})$ dissolved in $76 \%$ ethanol $(74 \mathrm{~m} l)$ with continuous stirring, and then distilled water $(150 \mathrm{~m} l)$ was added drop by drop to this suspension to form the ZeinMED. In both methods, the Zein-MED was collected by centrifugation $(1,500 \mathrm{rpm}, 15 \mathrm{~min})$ at $0^{\circ} \mathrm{C}$.

Diets 10 and 11 are the powdered diet with a zein-coating, which we classified as micro-coating diets (MCD). The Zein-MCD was prepared as follows. The formulated diets (pellet or semi-

*1 Faculty of Fisheries, University of Kagoshima, 50-20, Shimoarata-4, Kagoshima 890, Japan (金沢炤夫 • 手島新一・䇴田 博: 鹿児島大学水産学部).

*2 Present address: Fisheries Research Laboratory, Faculty of Agriculture, University of Tokyo, Ben-

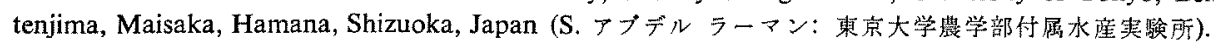


Table 1. Diets used in feeding experiments with the larvae of $P$. japonicus

\begin{tabular}{cllcc}
$\begin{array}{c}\text { Group } \\
\text { (Diet No.) }\end{array}$ & \multicolumn{1}{c}{ Type of diet } & \multicolumn{1}{c}{ Ingredient } & $\begin{array}{c}\text { Size } \\
(\mu \mathrm{m})\end{array}$ & $\begin{array}{c}\text { Feeding concentration } \\
\text { (mg/larva/day) }\end{array}$ \\
\hline 1 & Nylon-MED & Mysid extract +Chicken eggs & $50-100$ & $0.44-0.60^{* 3}$ \\
2 & Nylon-MED & Diet A ${ }^{* 1}+$ Chicken egg & $50-100$ & $0.44-0.60$ \\
3 & Nylon-MED & $\begin{array}{l}\text { Diet A free of lipids +Chicken } \\
\text { eggs }\end{array}$ & $50-100$ & $0.44-0.60$ \\
4 & Zein-MED (EtOH-method) & Mysid extract & $100-150$ & 0.33 \\
5 & Zein-MED (EtOH-method) & Diet A & $100-150$ & 0.33 \\
6 & Zein-MED (NaOH-method) & Diet A & $100-150$ & 0.33 \\
7 & Zein-MED (EtOH-method) & Diet A free of lipids & $100-150$ & 0.33 \\
8 & Zein-MED (EtOH-method) & Diet A free of cholesterol & $100-150$ & 0.33 \\
9 & Zein-MED (NaOH-method) & Diet B*2 & $100-150$ & 0.33 \\
10 & Zein-MCD & Diet A & $10-50$ & 0.20 \\
11 & Zein-MCD & Diet B & $10-50$ & 0.20 \\
12 & Live food & Chaetoceros, Artemia & & \\
13 & No food & & & \\
\hline
\end{tabular}

*1 Artificial diet for the prawn $P$. juponicus, designed by Kanazawa el al ${ }^{8}$

*2 Commercial diet for the prawn P. japonicus, (Evian, Kyowamhakko Kogyo Co. Ltd.).

*3 $\quad 500-700$ capsules $/ \mathrm{ml}$ water were supplied.

solid diet) were dried, crushed, and sieved through a mesh. To the powdered diets $(8 \mathrm{~g})$, zein $(5 \mathrm{~g})$ dissolved in $60 \%$ ethanol $(25 \mathrm{~m} l)$ was added, mixed thoroughly, and then heated in an oven at $40^{\circ} \mathrm{C}$ for $24-48 \mathrm{hr}$. The dried diets were powdered into particles $(10-50 \mu \mathrm{m})$.

The diatom Chaetoceros gracilis was cultured as described previousily. ${ }^{\text {B }}$

\section{Prawn Larvae and Feeding Experiments}

Eggs of the prawn $P$. japonicus were hatched in laboratory tanks. The feeding experiments on the test diets (Table 1) were carried out during the period of August 9 to August 16, 1979, by using the larvae of zoea ${ }_{1}$ stage which were came from the same spawner. In each experimental group, 100 zoea $_{1}$ larvae were put into a $1 /$-beaker containing $800 \mathrm{~m} l$ of the filtered sea water and reared with the test diet. Control groups of larvae (diet 12) were fed on C. gracilis (50-70,000 cells/ $\mathrm{m} /$ ) until mysis stage and then on Artemia salina (15 nauplii $/ \mathrm{m} l$ ). The apparatus and feeding methods were the almost same as those mentioned in the previous paper. ${ }^{5)}$ All the larvae in each beaker were counted and staged at 1-day interval. The dietary values of diets were evaluated in terms of survival rates and developmental stages of larvae as described in the previous paper. ${ }^{0}$

\section{Results}

In the present study, 11 kinds of the MD were prepared and the dietary values for the larvae of $P$. japonicus were examined by the feeding trials.
Table 2. Growth and survival of $P$. japonicus fed on the various types of diets

\begin{tabular}{ccc}
\hline $\begin{array}{c}\text { Diet } \\
\text { No. }\end{array}$ & $\begin{array}{c}\text { Survival }(\%) \\
\text { at } \mathrm{P}_{1}\end{array}$ & $\begin{array}{c}\text { Developmental } \\
\text { stage reached }{ }^{* 1}\end{array}$ \\
\hline 1 & 78 & $\mathrm{P}_{1}(8$ days)*2 \\
2 & 70 & $\mathrm{P}_{1}(8$ days $)$ \\
3 & 48 & $\mathrm{P}_{1}(8$ days $)$ \\
4 & 42 & $\mathrm{P}_{1}(8$ days $)$ \\
5 & 0 & $\mathrm{M}_{1}(5$ days $)$ \\
6 & 0 & $\mathrm{M}_{2}(5$ days $)$ \\
7 & 0 & $\mathrm{Z}_{3}(5$ days $)$ \\
8 & 0 & $\mathrm{M}_{1}(5$ days $)$ \\
9 & 67 & $\mathrm{P}_{1}(8$ days $)$ \\
10 & 94 & $\mathrm{P}_{1}(8$ days $)$ \\
11 & 75 & $\mathrm{P}_{1}(8$ days $)$ \\
12 & 95 & $\mathrm{P}_{1}(7$ days $)$ \\
13 (starved) & 0 & $\mathrm{Z}_{2}(3$ days) \\
\hline
\end{tabular}

*1 Developmental stages were abbreviated as follows: Zeoar $\left(Z_{2}\right)$ zoea $_{3}\left(Z_{3}\right)$, mysis $\left(M_{1}\right)$, mysis ${ }_{2}\left(M_{2}\right)$, mysis ${ }_{3}\left(M_{2}\right)$, and postlarvae $_{1}\left(P_{1}\right)$.

*2 Zoea $_{1}\left(Z_{1}\right)$ grew up to $P_{1}$ in 8 days.

The results are shown in Table 2 and Figs, 1, 2 , and 3.

Fig. 1 shows the survival and growth of the prawn larvae fed on the Nylon-MED. In all 3 diets, the prawn larvae grew from zoea ${ }_{1}$ to postlarvae $\left(\mathbf{P}_{1}\right)$ in 8 days. Also, a high survival rate was attained on the diets 1 and 2 . However, the retrenchment of lipids from the diet 2 resulted in the decrease of survival rate, indicating the necessity of lipids for the larval prawns. JoNes et al..$^{\text {s) }}$ have reported the success in rearing the prawn larvae from zoea ${ }_{1}$ to $\mathbf{P}_{1}$ with the Nylon-MED containing a mixture of short necked clam and 

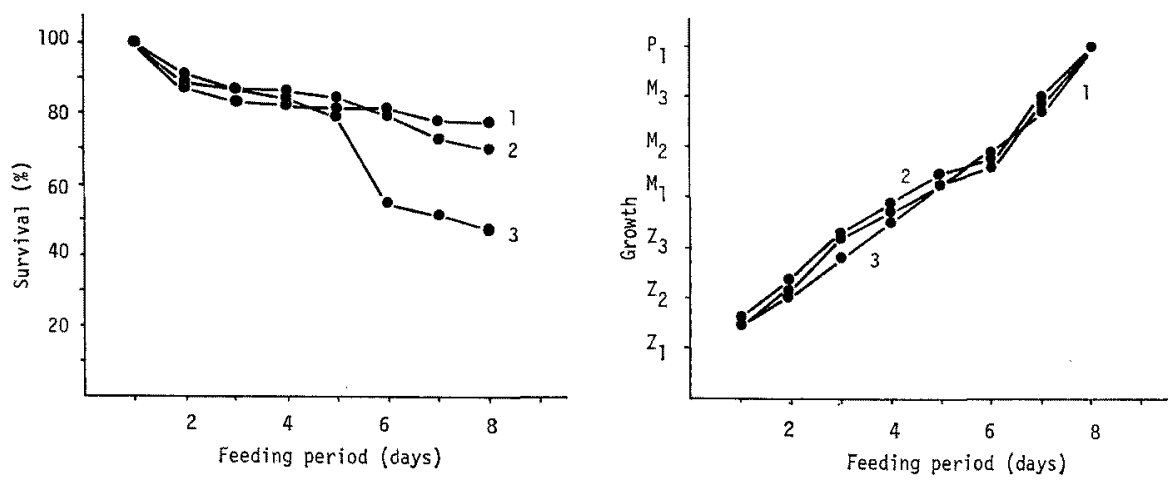

Fig. 1. Growth and survival rates of the prawn larvae fed on the Nylon-MED. Numerals indicate the diet No. (see Table 1).
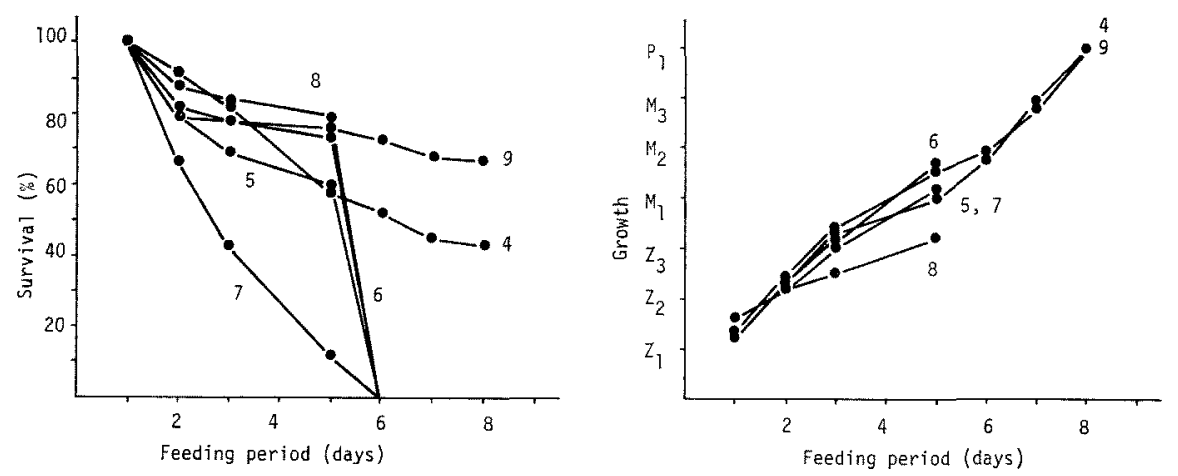

Fig. 2. Growth and survival rates of the prawn larvae fed on the Zein-MED. Numerals indicate the diet No. (see Table 1).
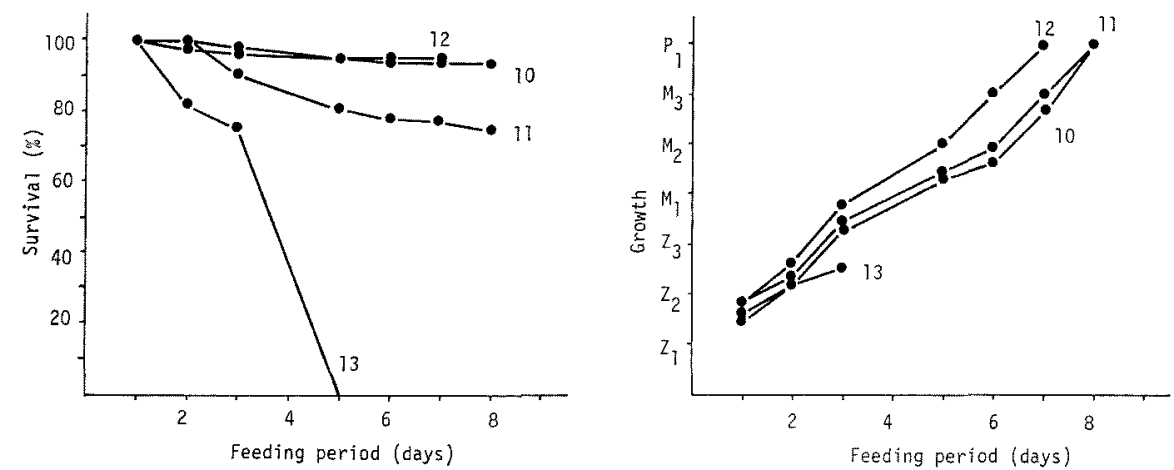

Fig. 3. Growth and survival rates of the prawn larvae fed on the Zein-MCD and live feeds. Numerals indicate the diet No. (see Table 1).

whole chicken egg (1:1) in 12 days, with the survival rate of $50 \%$. As compared with their results, the Nylon-MED containing diet $A$ and chicken egg seemed to be a superior diet in terms of both the survival and growth rates. The results may predict the possibility of rearing the prawn larvae by using the Nylon-MED containing a defined diet.

Fig. 2 shows the survival and growth of the prawn larvae fed on the Zein-MED. Two the Zein-MED containing mysid extract (diet 4) and commercial diet (diet 9) supported the growth of 
larvae from zoea ${ }_{1}$ to $P_{1}$. The survival rates on the diets 4 and 9 after 8 days, when the zoea grew up to $P_{1}$, were $42 \%$ and $67 \%$, respectively. All other Zein-MED only supported the growth of prawn larvae until mysis ${ }_{1}-$ mysis $_{2}$ stages, and all the larvae died in 6 days. Thus, the Zein-MED containing chemically defined diets were revealed to be imperfect as the diet for the prawn larvae. This seemed to be due not always to the insufficiency of nutrients but to other factors such as the stability of the diets in water, etc. GATESOUPE and LUQUET ${ }^{\text {9) }}$ have studied the water stability of the diets prepared by the several methods, and revealed that the water stability of the unprotected diet was very low; only $3 \%$ of the diets were recovered by filtration after $4 \mathrm{hr}$ in water. Furthermore, they have shown that the water-standing capacity was higher in the particles encapsulated with natural polymers such as gelatin and zein (stability, $74-79 \%$ ) than in the particles encapsulated with nylon (stability, 56-66\%). About the Zein-MED containing defined diets, it was thought advisable to check the leaking of nutrients during the encapsulation process and the completeness of encapsulation in coming investigation.

Fig. 3 shows the survival and growth of the prawn laryae fed on the Zein-MCD. Two the Zein-MCD containing diet A (diet 10) and commercial diet (deit 11) sustained the growth of prawn larvae from $z_{0 e a_{1}}$ to $P_{-1}$. The survival rates on the diets 10 and 11 after 8 days, when the zoea grew up to $P_{1}$, were $94 \%$ and $75 \%$, respectively. Except for an 1-day tardiness of growth to $P_{1}$, the Zein-MCD containing diet $A$ was almost comparable to the live feeds (diet 12) in respect to the dietary values. Since the diet 10 was composed of all chemically known compounds, we believe that this type of particulate diets will provide an effective method for determination of nutritional requirements in the larval prawns.

\section{Discussion}

There are several attempts to improve the techniques for rearing the larvae of $P$. japonicus by using baker's yeast and fermented soybean cake as supplements to planktonic feeds such as diatoms and Artemia..$^{10-12)}$ Crustacean larvae have been revealed to accept artificial food particles..$^{13-15)}$ In fact, a compounded diet has been demonstrated to support the growth and survival of larval prawn $P$. japonicus to some extent when it was powdered and supplied as acceptable particles. ${ }^{(3)}$ However, unprotected diets are generally susceptible to disintegration and bacterial attack. ${ }^{10}$ ) To resolve these problems, hence, JONEs and coworkers have prepared the Nylon-MED and reared several species of crustacean larvae. ${ }^{18-20)}$ For the prawns and Artemia, some Nylon-MED have been shown to give a high dietary value. ${ }^{b, 17)}$

The results of the present study also showed that the Nylon-MED containing a whole chicken egg and either mysid extract or artificial diet sustained the growth of prawn larvae to postlarval stage $\left(\mathbf{P}_{1}\right)$ with considerably high survival rates. The attempts to rear the larval prawns with the Zein-MED containing a defined diet were unsuccessful. Whereas, the Zein-MCD containing a defined diet sustained the growth and survival to post-larval stage $\left(\mathrm{P}_{1}\right)$ as observed on natural feeds, Chatoceros and Artemia. As far as we know, this paper is the first one showing the success in rearing the prawn larvae from $z^{2} e_{1}$ to post-larva $\left(P_{1}\right)$ with the particulate diet containing all chemically defined ingredients.

\section{Acknowledgements}

The authors wish to thank Kyowa Hakko Kogyo Co., Ltd. for supplying the commercial diet for the prawn. This work was supported in part by a grant from the Ministry of Education of Japan.

\section{References}

1) M. Fujinaga: Jap. J. Zool., 10, 305-393 (1942).

2) M. Fujinaga and M. Miyamura: Breeding of the Kuruma Prawn (Penaeus japonicus BATE). $J$. Oceanog. Soc. Japan (20th Anniversary Vol.), pp. 694-706 (1962).

3) M. Fujinaga and J. Kittaka: Inf. Bull. Planktol. Japan, 13, 83-94 (1966).

4) J. KItTAKa: "Through Culture of Inshore Fishes (in Japanese)", Koseisha-Koseikaku, Tokyo, 1971, pp. 344-408.

5) D. A. Jones, A. Kanazawa, and S. Abdel RAHMAN: Aquaculture, 17, 33-43 (1979).

6) C. T. Villegas and A. Kanazawa: Mem. Kagoshima Univ. Res. Center S. Pac., 1, 43-49 (1980).

7) T. M. S. Chang, F. C. MacIntosh, and S. C. Mason: Can. J. Physiol. Pharmacol., 44, 115128 (1966).

8) A. Kanazawa, S. Teshima, and S. Tokiwa: Bull. Japan. Soc. Sci. Fish., 43, 849-856 (1977). 
9) F. Gatesoupe and P. Luquet: 3rd Meeting of the I.C.E.S. Working Group on Mariculture, Brest, France, May 10-13, 1977. Actes de Colloques du C.N.E.X.O., 4, 131-145 (1977).

10) A. Brown, Jr.: Proc. Natn. Shellfish Ass., 62, 21-25 (1972).

11) I. Furukawa: Yoshoku (Fish-culture), 105, 3842 (1972).

12) H. Hirata, Y. Mori, and M. Watanabe: Marine Biol., 29, 9-13 (1975).

13) S. W. LING: FAO Fish. Rep., 75, 607-619 (1969).

14) G. A. Paffenhofer and J. D. H. Strickland: Marine Biol., 5, 97-99 (1970).

15) D. A. Jones, T. JAWED, and P. TILY: Chemosphere, 3, 133-136 (1972).

16) D. A. Jones, J. G. Munford, and P. A. GabBott:
Nature, 247, 233-235 (1974).

17) D. A. Jones and P. A. GabBott: in "Proceedings of the 2nd International Symposium on Microencapsulation" (ed. by J. R. NIxoN), Marcel Dekker Inc., New York, 1976, pp. 77-91.

18) D. A. Jones, T. H. Möller, R. J. Cambell, J. G. Munford, and P.A. GabBotT: in "Proceedings of the 10th European Symposium of Marine Biology, Oostend, Belgium, 1975" (ed. by G. Persoone and E. Jaspers), Vol. 1, Crustacea, Universa Press, Wetteren, 1976, pp. 229-239.

19) T. H. Möller, D. A. Jones, and P. A. Gabbott: in "Proceedings of the 3rd International Symposium on Microencapsulation" (ed. by T. Kondo), Techno Inc., Tokyo, 1979, pp. 223-229. 